\title{
Optimisation of PCR reactions using primer chessboarding
}

\author{
Rory Gunson, Graeme Gillespie, William F Carman* \\ West Of Scotland Specialist Virology Centre, A Member of the UK Clinical Virology Network, Gartnavel General Hospital, 1053 Great \\ Western Road, Glasgow G12 OYN, UK
}

Accepted 23 December 2002

\begin{abstract}
In-house polymerase chain reaction (PCR) assays are now an integral part of the work of most diagnostic microbiological laboratories. Despite the availability of commercial reagent 'master-mixes' of some PCR reagents, the optimisation of primers still poses a significant problem. Here, we describe a simple method to assess the concentration of primer needed in single round, multiplex, nested and 'real-time' PCR procedures.
\end{abstract}

(C) 2003 Elsevier Science B.V. All rights reserved.

Keywords: Polymerase chain reaction; Reagent; Primer

\section{Introduction}

In-house polymerase chain reaction (PCR) assays are an integral part of the work of most diagnostic microbiological laboratories. The quality control of reagents is an essential component of all successful in-house PCR assays. Despite the development of commercial master-mixes containing standardised concentrations of some PCR reagents, the standardisation of primers still poses a significant problem. The introduction of a new batch (which have been reconstituted at the required concentration according to the manufacturer's instructions) can result in a significant loss of sensitivity. This is despite most companies providing an optical density (OD) reading and

\footnotetext{
* Corresponding author. Tel.: +44-141-211-0080; fax: +44141-211-0082.

E-mail address: w.carman@vir.gla.ac.uk (W. F Carman).
}

nanomole values that can be used to dilute primers to the appropriate concentration. However, the way primers are manufactured (Invitrogen website) suggests that laboratories should not rely on these values to provide an accurate measure of their concentration.

First, a base is attached to a solid support to anchor the growing oligonucleotide chain (usually glass or polystyrene based) and then each base is added to the $3^{\prime}$ end during a series of coupling reactions. The coupling efficiency is usually in the region of $99 \%$. As a result, there is a small percentage of failure sequences (uncoupled oligonucleotides) present within the primer mix; the percentage of these increases with the length of primer being synthesized. Various purification techniques (e.g. HPLC, PAGE, Cartridge) are used to remove the failure sequences. However, some remain which can affect the PCR assay in two ways. 
Table 1

The PCR reagents

\begin{tabular}{lccc}
\hline Reagent & Conventional PCR $(\mu \mathrm{l})$ & Primer 1 master-mix $(\mu \mathrm{l})$ & Primer 2 master-mix $(\mu \mathrm{l})$ \\
\hline Proprietary PCR master-mix & 25 & 12.5 & 12.5 \\
Primer 1 (at appropriate concentration) & 0.5 & 0.5 & 0 \\
Primer 2 (at appropriate concentration) & 0.5 & 0 & 0.5 \\
DNAse RNAse free water & 14 & 7 & 7 \\
Total reaction volume & 40 & 20 & 20 \\
\hline
\end{tabular}

First, failure sequences can bind to the template and interfere with the PCR reaction, using up reagents and forming non-specific products. Second, the presence of these sequences will be included in the $\mathrm{OD} / \mathrm{nM}$ readings. As a result, when primers are reconstituted, the actual concentration of each working primer will vary depending on the amount of failure sequences present. Adding the wrong concentration of primer to a PCR is likely to reduce the sensitivity. Although numerous primer reagent optimization protocols (Caetano-Anolles, 1998; Cobb and Clarkson, 1994) have been published, most are complex and unsuitable for routine application.

Here, we describe a simple method to assess the concentration of primer needed in single round, multiplex, nested and 'real-time' PCR procedures.

\section{Method of chessboard procedure}

This method requires a range of primer 1 concentrations to be run against a range of primer 2 concentrations in the form of a matrix or chessboard. In the following example, primers 1 and 2 are tested between the concentrations of 100

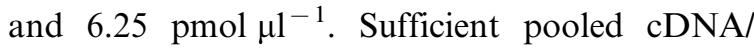
DNA must be available to ensure that each positive control is at the same concentration.

1) Reconstitute the primers to a stock dilution

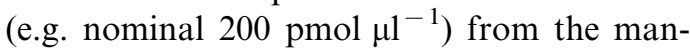
ufacturers' data.

2) Make 5 doubling dilutions of each primer to give $100,50,25,12.5$ and $6.25 \mathrm{pmol}^{-1} \mathrm{1}^{-1}$ of primer 1 and 2 .
3) For each primer concentration, make a master-mix with the appropriate volume of primer and half the volume of the remaining reagents (Table 1). In this example, there will be 5 PCR reactions in each column and row. Consequently, enough primer master-mix should be prepared for 6 PCR reactions per column and row.

4) Set out empty PCR tubes in the form of a $5 \times$ 5 matrix.

5) Aliquot half the final reaction volume of each of the primer 1 master mixes into the appropriate column. It is best to do this in descending concentrations.

6) Aliquot half the final reaction volume of each of the master mixes for primer 2 into the rows in descending concentration remembering to change the pipette tip with each reaction tube (Table 2). Each reaction tube will now contain the appropriate reaction volume.

7) Add template DNA/cDNA and carry out the PCR as normal.

8) Electrophoreses and visualise the products as described below.

\section{Examine PCR products on agarose gel}

Examine each band on an agarose gel. Bands should be graded on their brightness and the presence of non-specific banding patterns. The best band corresponds to the ideal primer concentration. An example of a chessboard is shown below (Fig. 1). Each band relates to a different primer concentration. Each 134 bp band has been examined and then graded accordingly (Table 3 ). 
Table 2

An outline of the primer chessboard

\begin{tabular}{|c|c|c|c|c|c|c|c|}
\hline & & $\begin{array}{l}\text { A } \\
\text { Primer } 1(100 \\
\left.\text { pmol } \mu 1^{-1}\right)\end{array}$ & $\begin{array}{l}\text { B } \\
\text { Primer } 1(50 \\
\left.\text { pmol } \mu 1^{-1}\right)\end{array}$ & $\begin{array}{l}\text { C } \\
\text { Primer } 1(25 \\
\left.\text { pmol } \mu 1^{-1}\right)\end{array}$ & $\begin{array}{l}\text { D } \\
\text { Primer } 1(12.5 \\
\left.\text { pmol } \mu 1^{-1}\right)\end{array}$ & $\begin{array}{l}\text { E } \\
\text { Primer } 1(6.25 \\
\left.\text { pmol } \mu 1^{-1}\right)\end{array}$ & $\begin{array}{l}\mathrm{F} \\
\text { Primer } 1(3.15 \\
\left.\text { pmol } \mu 1^{-1}\right)\end{array}$ \\
\hline 1 & $\begin{array}{l}\text { Primer } 2(100 \\
\left.\text { pmol } \mu l^{-1}\right)\end{array}$ & $40 \mu \mathrm{l}$ & $20 \mu \mathrm{l}$ & $40 \mu \mathrm{l}$ & $20 \mu \mathrm{l}$ & $20 \mu \mathrm{l}$ & $20 \mu \mathrm{l}$ \\
\hline 2 & $\begin{array}{l}\text { Primer } 2(50 \\
\left.\text { pmol } \mu l^{-1}\right)\end{array}$ & $40 \mu \mathrm{l}$ & $20 \mu \mathrm{l}$ & $40 \mu \mathrm{l}$ & $20 \mu \mathrm{l}$ & $20 \mu \mathrm{l}$ & $20 \mu \mathrm{l}$ \\
\hline 3 & $\begin{array}{l}\text { Primer } 2(25 \\
\left.\text { pmol } \mu 1^{-1}\right)\end{array}$ & $20 \mu \mathrm{l}$ & & $20 \mu \mathrm{l}$ & & & \\
\hline 4 & $\begin{array}{l}\text { Primer } 2(12.5 \\
\left.\text { pmol } \mu 1^{-1}\right)\end{array}$ & $20 \mu \mathrm{l}$ & & $20 \mu \mathrm{l}$ & & & \\
\hline 5 & $\begin{array}{l}\text { Primer } 2(6.25 \\
\left.\text { pmol } \mu 1^{-1}\right)\end{array}$ & $20 \mu \mathrm{l}$ & & $20 \mu \mathrm{l}$ & & & \\
\hline 6 & $\begin{array}{l}\text { Primer } 2(3.12 \\
\left.\text { pmol } \mu \mathrm{l}^{-1}\right)\end{array}$ & $20 \mu \mathrm{l}$ & & $20 \mu \mathrm{l}$ & & & \\
\hline
\end{tabular}

The method is illustrated with half volume of primer 1 PCR master-mix being added to column A and C with half volume primer 2 PCR master-mix added to row 1 and

Table 3

Example of primer chessboard results

\begin{tabular}{|c|c|c|c|c|c|c|c|}
\hline & & $\begin{array}{l}\text { A } \\
\text { Primer } 1(100 \\
\left.\text { pmol } \mu 1^{-1}\right)\end{array}$ & $\begin{array}{l}\text { B } \\
\text { Primer } 1(50 \\
\left.\text { pmol } \mu 1^{-1}\right)\end{array}$ & $\begin{array}{l}\mathrm{C} \\
\text { Primer } 1(25 \\
\left.\text { pmol } \mu 1^{-1}\right)\end{array}$ & $\begin{array}{l}\text { D } \\
\text { Primer } 1(12.5 \\
\left.\text { pmol } \mu 1^{-1}\right)\end{array}$ & $\begin{array}{l}\text { E } \\
\text { Primer } 1(6.25 \\
\left.\text { pmol } \mu 1^{-1}\right)\end{array}$ & $\begin{array}{l}\text { F } \\
\text { Primer } 1(3.175 \\
\left.\text { pmol } \mu 1^{-1}\right)\end{array}$ \\
\hline 1 & $\begin{array}{l}\text { Primer } 2(100 \\
\left.\text { pmol } \mu 1^{-1}\right)\end{array}$ & ++ & ++ & ++ & ++ & ++ & ++ \\
\hline 2 & $\begin{array}{l}\text { Primer } 2(50 \\
\left.\text { pmol } \mu 1^{-1}\right)\end{array}$ & ++ & ++ & +++ & +++ & +++ & ++ \\
\hline 3 & $\begin{array}{l}\text { Primer } 2(25 \\
\left.\text { pmol } \mu 1^{-1}\right)\end{array}$ & ++ & ++ & +++ & +++ & \pm \pm \pm \pm & ++ \\
\hline 4 & $\begin{array}{l}\text { Primer } 2(12.5 \\
\left.\text { pmol } \mu \mathrm{l}^{-1}\right)\end{array}$ & + & ++ & +++ & +++ & \pm \pm \pm \pm & ++ \\
\hline 5 & $\begin{array}{l}\text { Primer } 2(6.25 \\
\left.\text { pmol } \mu 1^{-1}\right)\end{array}$ & + & ++ & ++ & ++ & ++ & + \\
\hline 6 & $\begin{array}{l}\text { Primer } 2(3.175 \\
\left.\text { pmol } \mu 1^{-1}\right)\end{array}$ & + & + & + & + & + & + \\
\hline
\end{tabular}



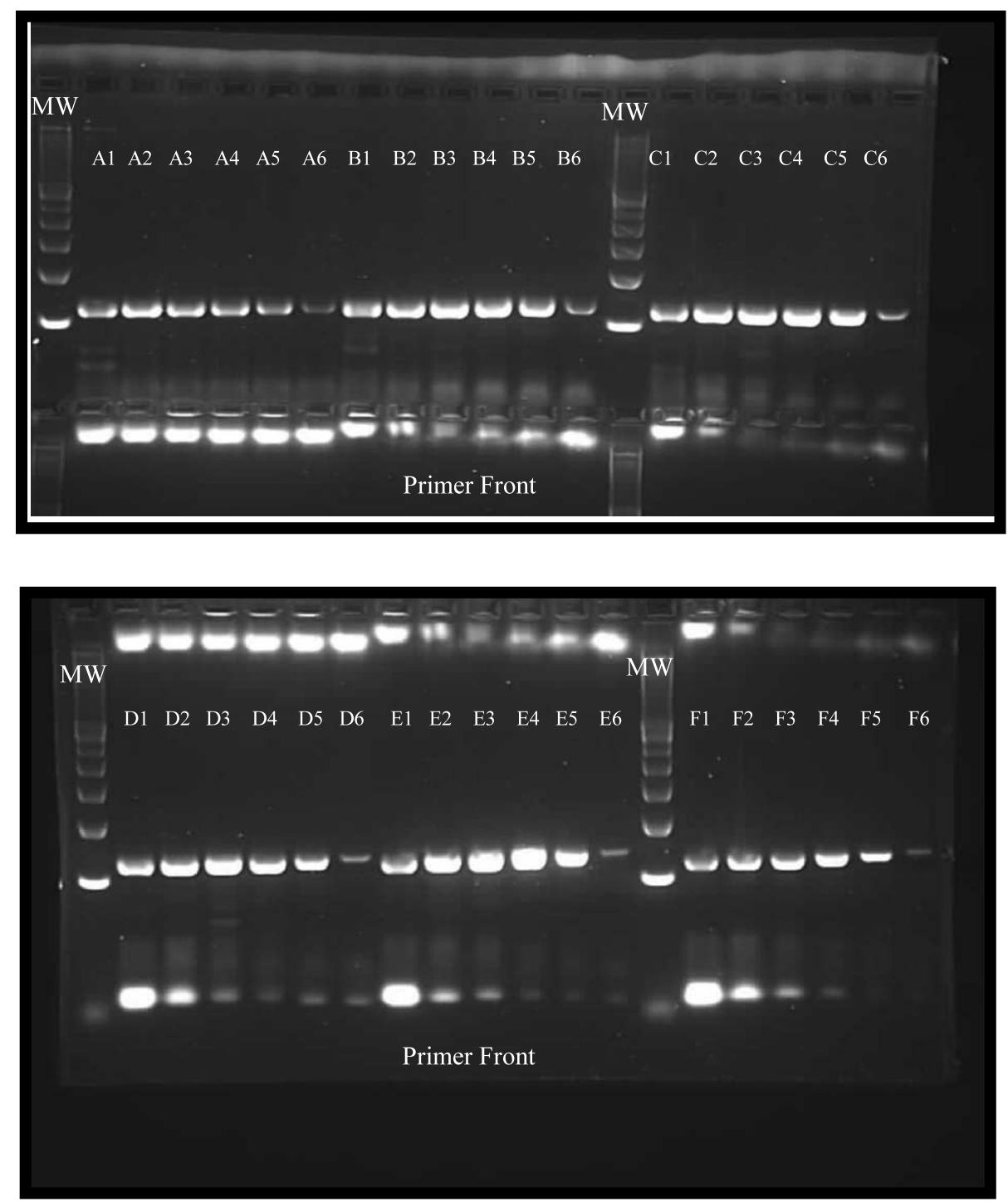

Fig. 1. Primers 1 and 2 are tested between the concentrations of 100 and $6.25 \mathrm{pmol} \mu 1^{-1}$. Each band relates to a different primer concentration. Bands should be graded on their brightness and the presence of non-specific banding patterns (Table 3 ). The best band corresponds to the ideal primer concentration. In this example bands E3 and E4 are the optimal primer concentration. 


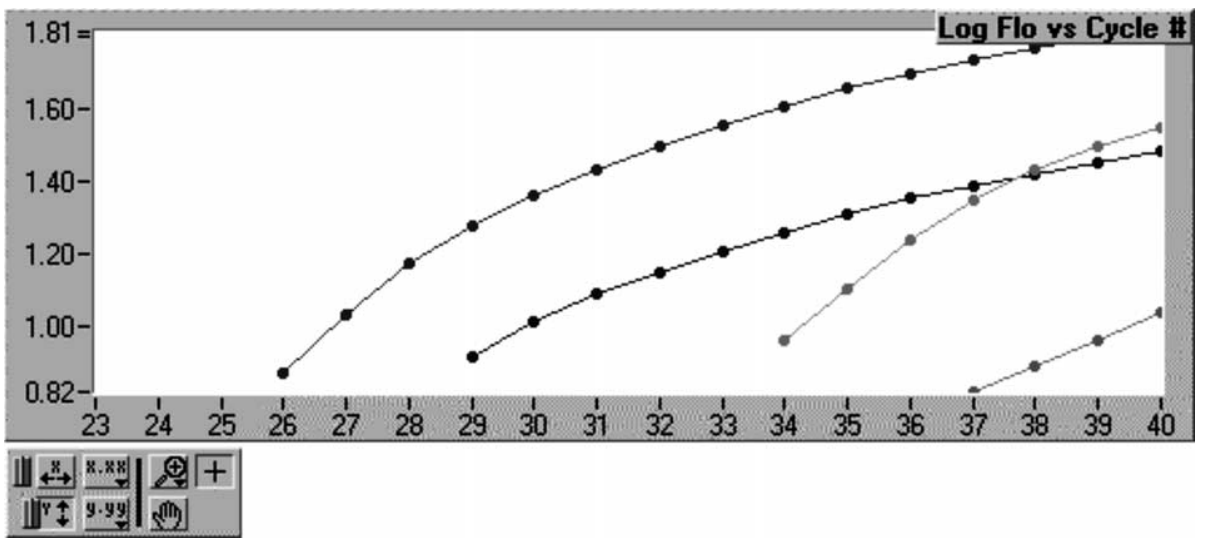

Fig. 2. Chessboard results for 4 different PCR reactions (A, B, C and D) each with differing primer 1 and primer 2 concentrations. PCR A is positive earlier than the other three assays, indicating that the primers are at the appropriate concentration.

\section{Protocol for real-time PCR}

The protocol for real-time PCR only differs at the reading phase. The concentration of primer will determine which cycle a sample becomes positive (i.e., when product becomes detectable). The ideal primer concentration corresponds with the earliest cycle at which a sample becomes positive (Fig. 2)

\section{Protocol for multiplex PCR}

Carry out the above protocol for the each set of primers in the multiplex as a separate single round PCR.

\section{Protocol for nested PCR}

Carry out the above protocol for both rounds of PCR. If possible, analyse first round products on a gel and determine which primer concentration offers the best sensitivity for the first round PCR. Repeat the chessboard using the second round primers (using either the best product taken from the first round chessboard or a positive control) to determine ideal primer concentration for the second round. Carrying out chessboard reactions on a nested multiplex PCR assay is not recommended, as the number of possible combinations of primer concentrations will be very large.

\section{Results and discussion}

We have carried out primer chessboard reactions on all new batches of primers and have found that both too much and too little concentration of each primer can reduce the sensitivity of the PCR, which may lead to false negative results.

We recommend that new batches of primer should be assessed before their introduction into routine use. It is good laboratory practice to carry this out weeks prior to the introduction of new primers into routine use. By carrying out the 'primer chessboarding' method one can establish the correct working strength of each primer. We have found this method to be repeatable and in the majority of cases this has documented batch differences in the concentration of primer needed for PCR and resulted in a change of standard operating procedure.

\section{References}

Invitrogen website available from http://www.invitrogen.com.

Caetano-Anolles G. DAF optimization using Taguchi methods and the effect of thermal cycling parameters on DNA amplification. Biotechniques 1998;25:472-6.

Cobb DB, Clarkson JM. A simple procedure for optimizing the polymerase chain reaction (PCR) using modified Taguchi methods. Nucleic Acids Res 1994;22:3801-5. 